\title{
Adenovirus-mediated gene transfer in the ovine pituitary gland is associated with hypophysitis
}

\author{
J R E Davis, R F T McMahon ${ }^{1}$, P R Lowenstein², M G Castro², \\ G A Lincoln ${ }^{3}$ and A S McNeilly ${ }^{3}$ \\ Endocrine Sciences Research Group, Faculty of Medicine, University of Manchester, Manchester, UK \\ ${ }^{1}$ Laboratory Medicine Academic Group, Faculty of Medicine, University of Manchester, Manchester, UK \\ ${ }^{2}$ Molecular Medicine and Gene Therapy Unit, Faculty of Medicine, University of Manchester, Manchester, UK \\ ${ }^{3}$ MRC Human Reproductive Sciences Unit, Chalmers Street, Edinburgh, UK \\ (Requests for offprints should be addressed to J R E Davis, Endocrine Sciences Research Group, Faculty of Medicine, University of Manchester, \\ Manchester M13 9PT, UK; Email: julian.davis@man.ac.uk) \\ (M G Castro and P R Lowenstein are now at Cedars-Sinai Medical Center, Gene Therapeutics Institute, Davis Building, 8700 Beverly Boulevard, Los Angeles, \\ California 90048, USA)
}

\begin{abstract}
Gene therapy for pituitary disease requires evaluation for safety as well as efficacy. We have reported results of adenovirus-mediated gene transfer using the sheep as a large animal model that allows longitudinal evaluation of hormone secretion and have confirmed high levels of transgene expression up to 7 days after direct stereotaxic injection into the pituitary gland. Here we report the results of detailed histological examination of the pituitary glands from animals injected with two recombinant adenoviruses expressing the $\beta$-galactosidase marker gene, or with saline vehicle to control for the potential tissuedisruptive effect of the injection volume itself. Pituitaries injected with saline showed no evidence of inflammatory response apart from occasional minor foci of apoptosis. In all other respects they were indistinguishable from normal uninjected control pituitary glands. Glands injected with recombinant adenoviruses containing either
\end{abstract}

the hCMV- $\beta$-gal or the hPRL- $\beta$-gal transgene, on the other hand, displayed variable degrees of inflammatory response, with periglandular fibrosis, lymphocytic infiltrate and venulitis in almost all cases. Focal necrosis and/or apoptosis was noted in six of nine cases.

In summary, we have found evidence of severe inflammatory reaction within the first seven days of adenovirus injection, amounting to significant hypophysitis. The histological extent of this reaction has not previously been recognised by studies of the efficacy of gene transfer in rodents, and was underestimated by immunocytochemical studies of hormone and transgene expression. The findings emphasise the need for careful evaluation of the safety of endocrine gene therapy, and for caution with the dose of vector used.

Journal of Endocrinology (2002) 173, 265-271

\section{Introduction}

Pituitary tumours are conventionally treated by transsphenoidal or transfrontal surgery, external beam irradiation, or with long-term suppressive drug therapy. Although these approaches are widely accepted, they have significant shortcomings, such as lifelong hypopituitarism and drug side-effects (Davis et al. 1999). For those tumours that are particularly aggressive or the rare malignant cases that have metastasised, existing therapy is often of little or no benefit. For these reasons, interest has grown in the possibility of exploiting gene therapy approaches for pituitary disease (Castro 1999, Davis et al. 1999, Barzon et al. 2000, Castro et al. 2001, Davis \& McNeilly 2001). Adenoviral gene transfer is also a potentially attractive approach for studies of pituitary physiology and a variety of in vitro and in vivo models are available for evaluation of the effects of therapeutic or interventional gene transfer.

Several studies have reported experience with adenoviruses as highly efficient tools for gene transfer into pituitary cells (Castro et al. 1997, Neill et al. 1998, Lee et al. 1999, 2000, Southgate et al. 2000, Windeatt et al. 2000). Recombinant adenoviruses infect all pituitary cell types effectively, as judged by monitoring marker genes such as $\beta$-galactosidase (Castro et al. 1997), and variable degrees of pituitary ablation have been achieved in rodent models using the herpes simplex virus thymidine kinase (HSV-TK) gene (Lee et al. 1999, Southgate et al. 2000, Windeatt et al. 2000). We have recently reported encouraging results using the sheep as a large animal model that allows longitudinal evaluation of hormone secretion, where we can achieve high-level transgene expression for 
at least 7 days after direct stereotaxic injection into the pituitary gland without disruption of normal endocrine function or any apparent ill effect (Davis et al. 2001).

Any potential application of gene therapy for pituitary disease in man, however, requires evaluation for safety as well as efficacy. Adenoviruses have been associated with significant inflammatory responses in several tissues (Byrnes et al. 1995). Work on the pituitary gland to date has suggested little apparent adverse effect (Southgate et al. 2000), but a transient inflammatory response in the rat pituitary has been reported, accompanied by a humoral response, both processes peaking at about 14 days after intrapituitary injection (Southgate et al. 2001). A significant pituitary inflammatory reaction might be clinically significant even if it was transient, and it is therefore of interest to assess its histological nature and extent. We analysed the pituitary gland sections from our previous work on direct stereotaxic injection in the ovine pituitary (Davis et al. 2001), and found surprisingly extensive leucocyte infiltration, despite a lack of any apparent systemic disturbance. We have, therefore, carried out a careful histological survey of these adenovirus-injected pituitary glands, and compared them with normal pituitary and control tissue after stereotaxic injection of the same volumes of saline vehicle. We found evidence of a severe inflammatory reaction associated with injection of the recombinant adenoviruses, with lymphocytic infiltrates, venulitis and periglandular fibrosis in all cases. The extent of this reaction in the pituitary was not suspected from longitudinal assessment of haematological and endocrine parameters. These findings emphasise the need for careful evaluation of possible adverse effects of viral gene transfer into the intact pituitary gland, especially in view of the known variation in immune response among different animal models (Ohmoto et al. 1999).

\section{Materials and Methods}

\section{Animals and stereotaxic pituitary injection}

The experimental procedure has been described in detail in our earlier report (Davis et al. 2001). Briefly, anoestrous Suffolk ewes (2-3 years old, 35-45 kg) were anaesthetised and a stereotaxic frame was set up. A burr-hole was made in the skull anterior to the bregma, and the location of the pituitary gland was deduced from lateral skull radiographs after instillation of radio-opaque dye into the cerebral spinal fluid to visualise the third ventricle (Mori et al. 1990, Lignereux et al. 1991). For injection of virus particles or of saline control, a fine-bore metal cannula was inserted stereotaxically and lowered to the base of the pituitary fossa. It was withdrawn $2 \mathrm{~mm}$, and $250 \mu \mathrm{l}$ viral vector or saline vehicle were injected into the pituitary gland at each of three levels. The cannula and guide needle were left in place for $1 \mathrm{~min}$, then both were completely withdrawn, reintroduced $2 \mathrm{~mm}$ anteriorly, and the procedure repeated. A third injection procedure was carried out posterior to the initial injection site. A total of nine sites were used to inject virus, using a total volume of approximately $2 \cdot 2 \mathrm{ml}$ injected over a period of 50-60 min.

\section{Adenovirus vectors}

Nine animals were injected with suspensions of recombinant adenovirus in normal saline, and four with saline or with saline containing a dilute suspension of India ink to help confirm the injection sites within the gland. Two alternative recombinant adenovirus vectors were used, based on adenovirus type 5, in which the E1 and part of the $\mathrm{E} 3$ regions were deleted. In one of these, $\mathrm{RAd}-\mathrm{CMV}-\beta$-gal (also termed RAd-35), the $\beta$-galactosidase gene is driven by the short immediate-early human cytomegalovirus (sMIEhCMV) promoter inserted in place of the E1 deletion (Castro et al. 1997). In the other vector (RAd-hPRL- $\beta$-gal) the promoter element comprised a $-4429 /+14$ fragment from the pituitary-specific promoter of the human prolactin gene (Berwaer et al. 1991, Takasuka et al. 1998), constructed as described (Southgate et al. 2000). Virus injections were prepared of RAd-hPRL- $\beta-G a l$ or RAd-hCMV- $\beta-G a l$, at a concentration that delivered approximately $1.5 \times 10^{8}$ pfu per site, giving a total of approximately $14 \times 10^{8} \mathrm{pfu}$ injected into the gland.

\section{Post-operative monitoring}

Blood sampling was carried out before surgery and then daily, via an indwelling jugular catheter as previously reported (Davis et al. 2001). Samples were analysed for hormones by radioimmunoassay, and for routine haematology by the Diagnostic Services laboratory, Department of Veterinary Clinical Studies, Easter Bush Veterinary Centre, Roslin, Midlothian, UK. The endocrine data have been reported previously for the virus-injected animals (Davis et al. 2001), and data for the saline-injected animals were similar and are not shown in this paper. Haematological data were available for four of the virus-injected animals and for all of the saline-injected animals and controls, and are given in full here for comparison with the histological findings. Animals were killed 4-7 days after virus injection with an overdose of intravenous pentobarbitone. The dura overlying the pituitary gland was examined for puncture holes, and the pituitary glands were dissected, divided sagittally into thirds, and placed into Bouin's fixative within $5 \mathrm{~min}$ of death. All experimental procedures were conducted in accordance with the Home Office Animals (Scientific Procedures) Act 1986 of the United Kingdom.

\section{Histopathology}

Tissues were routinely fixed in Bouin's fixative and processed into paraffin. Sections were cut at $4 \mu \mathrm{m}$ and stained with haematoxylin and eosin. 
Table 1 Haematological indices of animals on the day of pituitary collection. Values are shown for four of the adenovirus-injected animals (Ad), for four of the animals whose pituitary glands were injected with saline alone, and for four unoperated controls of the same breed. Laboratory control values (general ovine range, from Diagnostic Service Laboratories, Edinburgh) are shown for reference, and values outside this reference range are asterisked. Note that mild leucocytosis was common regardless of any operative procedure, and that both this and the neutrophilia seen in one virus-injected animal were not reliable markers for the histological evidence of pituitary inflammation (Table 2)

\begin{tabular}{|c|c|c|c|c|c|c|}
\hline & $\begin{array}{l}\text { Haemoglobin } \\
(\mathrm{g} / \mathrm{dl})\end{array}$ & $\begin{array}{l}\text { Total leucocytes } \\
\left(\times 10^{9} / \mathrm{l}\right)\end{array}$ & $\begin{array}{l}\text { Neutrophils } \\
\left(\times 10^{9} / \mathrm{I}\right)\end{array}$ & $\begin{array}{l}\text { Lymphocytes } \\
\left(\times 10^{9} / \mathrm{ll}\right)\end{array}$ & $\begin{array}{l}\text { Monocytes } \\
\left(\times 10^{9} / \mathrm{l}\right)\end{array}$ & $\begin{array}{l}\text { Eosinophils } \\
\left(\times 10^{9} / \mathrm{I}\right)\end{array}$ \\
\hline \multicolumn{7}{|l|}{$\begin{array}{l}\text { Injection } \\
\text { ID\# }\end{array}$} \\
\hline $\begin{array}{l}\text { Ad } \\
11 / 1639\end{array}$ & $11 \cdot 9$ & $7 \cdot 8$ & $2 \cdot 34$ & $5 \cdot 15$ & $0 \cdot 23$ & $0 \cdot 07$ \\
\hline $\begin{array}{l}\text { Ad } \\
12 / 1640\end{array}$ & $11 \cdot 2$ & $11 \cdot 4^{*}$ & $8.09^{*}$ & $0 \cdot 23^{*}$ & $2 \cdot 74^{\star}$ & $0 \cdot 23$ \\
\hline $\begin{array}{l}\text { Ad } \\
13 / 1703\end{array}$ & $10 \cdot 5$ & $6 \cdot 7$ & $2 \cdot 34$ & $3 \cdot 89$ & $0 \cdot 47$ & 0 \\
\hline $\begin{array}{l}\text { Ad } \\
14 / 1708\end{array}$ & $10 \cdot 3$ & $8 \cdot 9$ & $4 \cdot 27$ & $4 \cdot 45$ & $0 \cdot 18$ & 0 \\
\hline $\begin{array}{l}\text { Saline } \\
15 / 2294\end{array}$ & $10 \cdot 7$ & $9 \cdot 4$ & $2 \cdot 54$ & $6 \cdot 11$ & $0 \cdot 19$ & 0 \\
\hline $\begin{array}{l}\text { Saline } \\
16 / 2296\end{array}$ & $11 \cdot 9$ & $11 \cdot 8^{*}$ & $2 \cdot 48$ & $7 \cdot 55^{*}$ & $0 \cdot 59$ & $1 \cdot 06^{*}$ \\
\hline $\begin{array}{l}\text { Saline } \\
17 / 2298\end{array}$ & $11 \cdot 4$ & $7 \cdot 8$ & $1 \cdot 40$ & $5 \cdot 62$ & $0 \cdot 55$ & $0 \cdot 16$ \\
\hline $\begin{array}{l}\text { Saline } \\
18 / 2300\end{array}$ & $11 \cdot 1$ & $10 \cdot 7^{*}$ & $3 \cdot 42$ & $6 \cdot 42$ & $0 \cdot 32$ & $0 \cdot 53$ \\
\hline Control & $11 \cdot 5$ & $6 \cdot 6$ & $1 \cdot 85$ & $4 \cdot 42$ & $0 \cdot 20$ & $0 \cdot 13$ \\
\hline Control & $12 \cdot 1$ & $11 \cdot 4^{*}$ & $4 \cdot 90$ & $5 \cdot 70$ & $0 \cdot 34$ & $0 \cdot 34$ \\
\hline Control & $12 \cdot 5$ & $10 \cdot 8^{*}$ & $2 \cdot 70$ & $7 \cdot 24$ & $0 \cdot 11$ & $0 \cdot 76$ \\
\hline Control & $13 \cdot 0$ & $11 \cdot 3^{*}$ & $3 \cdot 05$ & $7 \cdot 34$ & $0 \cdot 23$ & $0 \cdot 68$ \\
\hline $\begin{array}{l}\text { Normal } \\
\text { range }\end{array}$ & 8-14 & $4-10$ & $0 \cdot 4-5 \cdot 0$ & $1 \cdot 6-7 \cdot 5$ & $<0.60$ & $<1 \cdot 0$ \\
\hline
\end{tabular}

\section{Results}

Animals injected with either adenovirus or with saline remained apparently well. Haematological parameters remained normal in most animals throughout the 7-day period of study after injection. Full details of differential leucocyte counts on the day of pituitary collection for histology are given in Table 1. Mild leucocytosis was seen in many animals, including unoperated controls of this breed, but a mild neutrophilia and relative lymphopaenia was seen in only one animal injected with adenovirus. Measurements of pituitary hormone secretion also remained normal (data not shown, previously reported in Davis et al. 2001).

On macroscopic and histological examination of the pituitary glands, needle tracks were clearly visible (Fig. 1, 1a), and in some but not all cases this was associated with microscopic haemorrhage within the parenchyma of the pituitary (Fig. 1, 1b). Pituitaries injected with saline showed no evidence of inflammatory response apart from two of eight animals where minor foci of apoptosis were noted (Fig. 1, 1c). In all other respects they were indistinguishable from normal uninjected control pituitary glands (Table 2).

Glands injected with recombinant adenoviruses containing either the hCMV- $\beta$-gal or the hPRL- $\beta$-gal transgene, on the other hand, displayed variable degrees of inflammatory response. The most prominent findings included marked periglandular lymphocytic infiltrate, oedema and fibrosis (Fig. 1, 2a), with associated venulitis in almost all cases (Fig. 1, 2b and 2c). Within the glandular tissue more minor degrees of inflammatory infiltrate were seen, with focal necrosis in five of the nine virus-injected animals (Fig. 1, 3a-c), and localised apoptosis in two (Table 2). It is noteworthy that the severity of the inflammatory reaction seen in the pituitary glands was not reflected by the relatively unaltered systemic haematological indices in these animals, shown in Table 1, implying that haematological monitoring is not an adequate guide to intra-pituitary inflammatory response. 


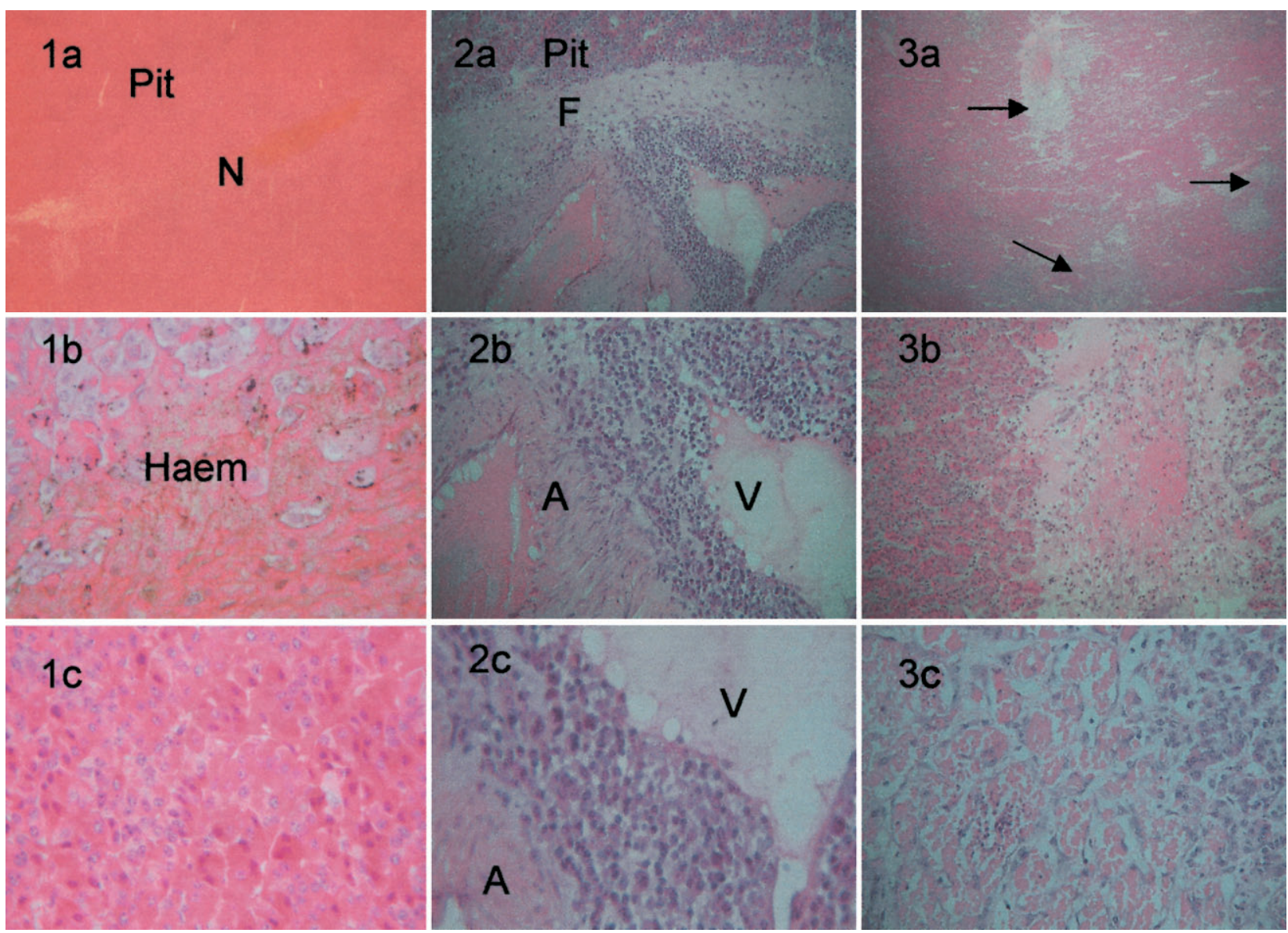

Figure 1 (1a) Low power view of pituitary gland injected with saline (\#15/2294) in which a needle track (N) associated with an area of haemorrhage is clearly visible. The gland (Pit) is otherwise normal (haematoxylin and eosin; magnification $\times 43$ ). (1b) Higher power view of the same gland showing haemosiderin-containing macrophages (dark brown granules) at the site of haemorrhage (Haem) (haematoxylin and eosin; magnification $\times 860$ ). (1c) High power view of a pituitary gland injected with saline (\#17/2298) displaying increased numbers of apoptotic cells, characterised by pyknotic, dark staining nuclei and granular, hypereosinophilic cytoplasm (haematoxylin and eosin; magnification $\times 430$ ). (2a) Pituitary gland injected with adenovirus (\#12/1640) demonstrating periglandular fibrosis (F) with intense lymphoid infiltrate around vessels but also extending into glandular tissue (Pit) (haematoxylin and eosin; magnification $\times 85$ ). $(2 \mathrm{~b})$ Higher power view of the same area, showing that the infiltrate mainly involves a venule (V) (to the right) with relative sparing of an adjacent arteriole (A) (to the left) (haematoxylin and eosin; magnification $\times 210$ ). (2c) Higher magnification shows that this infiltrate consists of lymphocytes, macrophages and plasma cells (haematoxylin and eosin; magnification $\times 430$ ). (3a) Low power view of a pituitary gland injected with adenovirus (\#13/1703) in which there are several foci of necrosis (arrows) (haematoxylin and eosin; magnification $\times 43$ ). (3b) Medium power view of the largest focus showing necrosis, oedema and inflammatory infiltration (haematoxylin and eosin; magnification $\times 85$ ). (3c) High power view showing coagulative necrosis (to the left) with occasional neutrophil polymorphs, alongside normal pituitary (to the right) (haematoxylin and eosin; magnification $\times 210$ ).

\section{Discussion}

A number of previous reports have confirmed the efficacy of adenoviral gene transfer into pituitary cells, both in vitro and in vivo. This has raised the possibility that gene therapy might be a viable future approach to the treatment of pituitary tumours in man (Castro 1999, Davis et al. 1999, Castro et al. 2001, Davis \& McNeilly 2001). Any future application of gene therapy to pituitary tumours will require careful evaluation of its safety, especially given that pituitary disease is generally not directly fatal. For this reason we have studied a large animal model that allows multi-parameter longitudinal assessment. Direct intra-pituitary injection of adenovirus appears to be necessary for adequate transgene expression within the pituitary gland (Lee et al. 2000). Cell-type specificity can be achieved by the use of pituitary gene promoters such as prolactin and growth hormone (Lee et al. 1999, Southgate et al. 2000, Davis et al. 2001), and this might, in principle, be useful to limit the cytotoxicity of intended ablative transgene expression to the intended target cell type. 
Table 2 Detailed histological findings for pituitary glands injected with adenovirus (Ad) or saline vehicle. The number of days elapsed after injection is shown, and histological details are shown separately for glandular tissue and periglandular tissue

\begin{tabular}{|c|c|c|c|c|c|c|c|c|c|c|}
\hline & & & Glandul & ar tissue & & & & Periglan & dular tissue & \\
\hline & Vector injected & $\begin{array}{l}\text { after } \\
\text { injection }\end{array}$ & Cells & Necrosis & Apoptosis & Inflammation & Haemorrhage & Fibrosis & $\begin{array}{l}\text { Inflammatory } \\
\text { infiltrate }\end{array}$ & Venulitis \\
\hline ID\# & & & & & & & & & & \\
\hline Ad5/1572 & RAd-CMV- $\beta$ gal & 3 & Normal & Focal & Nil & At edge & No & + & ++ & ++ \\
\hline Ad9/1582 & RAd-PRL- $\beta$ gal & 4 & Normal & Focal & Nil & Nil & No & $+/-$ & + & Nil \\
\hline Ad10/1586 & RAd-PRL- $\beta$ gal & 4 & Normal & $\mathrm{Nil}$ & Nil & Nil & No & + & $+/++$ & + \\
\hline Ad8/1630 & RAd-PRL- $\beta$ gal & 6 & Normal & Nil & $\mathrm{Nil}$ & Nil & No & + & +++ & +++ \\
\hline Ad6/1625 & RAd-CMV- $\beta$ gal & 7 & Normal & Focal & Focal & Nil & No & $+/-$ & + & + \\
\hline Ad11/1639 & RAd-PRL- $\beta$ gal & 7 & Normal & $\mathrm{Nil}$ & Focal & Mild & No & + & ++ & ++ \\
\hline Ad12/1640 & RAd-PRL- $\beta$ gal & 7 & Normal & Nil & Nil & At edge & No & ++ & ++ & +++ \\
\hline Ad13/1703 & RAd-CMV- $\beta$ gal & 7 & Normal & Several foci & Nil & Nil & No & $+/-$ & + & + \\
\hline Ad14/1708 & RAd-CMV- $\beta$ gal & 7 & Normal & Small foci & Nil & Nil & No & + & + & + \\
\hline $15 / 2294$ & Saline & 7 & Normal & Nil & Nil & Nil & Yes & Nil & Nil & Nil \\
\hline $16 / 2296$ & Saline+ink & 7 & Normal & Nil & Nil & Nil & Yes & $+1-$ & Nil & Nil \\
\hline $17 / 2298$ & Saline+ink & 7 & Normal & Nil & Focal & Nil & Yes & Nil & Nil & Nil \\
\hline $18 / 2300$ & Saline & 7 & Normal & Nil & Focal & Nil & Yes & Nil & Nil & Nil \\
\hline $\begin{array}{l}\text { Normal } \\
\text { pituitary }\end{array}$ & Uninjected & - & Normal & Nil & Nil & Nil & No & $+/-$ & Nil & Nil \\
\hline
\end{tabular}

The histological severity of inflammatory changes was graded: $+/-$ indicates minimal evidence, + indicates mild, ++ moderate, and +++ severe changes.

An inflammatory response to adenovirus injection has been reported in other tissues (Byrnes et al. 1995, Wood et al. 1996, Chan et al. 1999, Dewey et al. 1999, Thomas et al. 2000) but until recently this had not been considered a major problem until the death of a patient after systemic injection in 1999 (Marshall 1999). The immune response to adenovirus is thought to be primarily a T-lymphocytemediated response (Yang et al. 1994, Kajiwara et al. 1997, Chan et al. 1999), although recent evidence in the rat pituitary has implicated activated macrophages and NK cells, and also a neutralizing humoral immune response (Southgate et al. 2001). It remains unclear whether the inflammatory response is due to the adenoviral structural proteins or to adenoviral transgene expression (Yang et al. 1994, Tripathy et al. 1996, Thomas et al. 2000). Second generation, helper-virus-dependent ('gutless') vectors deleted of all viral genes may prove safer for use in this respect, and recent reports have suggested that these vectors are associated with substantially attenuated and transient inflammatory responses in the brain (Thomas et al. 2000, 2001).

Histological analysis of adenovirus-injected pituitary glands revealed a series of features of hypophysitis. Mild or moderate periglandular fibrosis was seen in six of the nine virus-injected animals, while only a minimal degree was seen in the controls. However, a periglandular inflammatory infiltrate of lymphoid cells was seen only after adenovirus injection and was intense in many of the cases and especially associated with blood vessels. These features are those of severe hypophysitis. The inflammatory infiltrate was composed of lymphoid cells showing morphological features of mature lymphocytes, macrophages and plasma cells. No polymorphonuclear cells were identified, suggesting that even as early as 7 days after injection the response was predominantly of an histologically chronic type, suggestive of an immune-mediated reaction to viral components. The end result of such inflammation is typically fibrous tissue production as seen here although the timescale is rather more rapid than might normally be expected. The site of needle puncture was confirmed by identification of needle shaped areas of haemorrhage, associated in places with accumulation of haemosiderin within macrophages. These sites of needle puncture did not themselves appear to be associated with significant necrosis, apoptosis or inflammation. Foci of necrosis were identified in the virus-injected animals, showing a typical coagulative necrosis pattern and a focal neutrophil polymorph infiltrate. In two of the animals injected with saline or India ink alone, increased numbers of apoptotic cells were identified, the exact significance of which is uncertain. These apoptotic cells were not associated with inflammatory cell infiltrates or necrosis. Similar foci of apoptosis were noted in two of the virus-treated animals. The finding of apoptotic cells in both groups and in similar numbers may indicate that this is a normal 'house-keeping' phenomenon whereby the pituitary responds to the stress of needle puncture by eliminating damaged cells in a controlled way. Thus apoptosis alone appears not to be a specific feature of virus-mediated damage.

The sheep pituitary is $10-12 \mathrm{~mm}$ in antero-posterior diameter, and we reported that a local injection of 
recombinant adenovirus can achieve effective transgene expression across substantial regions of the gland (Davis et al. 2001). However, the size of the sheep pituitary gland has also allowed us to assess the extent and pattern of inflammatory response in some detail. The extent of the inflammatory reaction that we have described in this report had not previously been recognised by studies of the efficacy of gene transfer in rodents, nor in our system by haematological profiles, immunocytochemical studies of hormone and transgene expression, or hormone secretion studies (Davis et al. 2001). Hypophysitis and pituitary infarction ('apoplexy') can present in various ways. Most important, swelling of the gland in the confined space of the pituitary fossa can threaten vision, requiring urgent pituitary surgery to relieve pressure effects on the optic chiasm (Cheung et al. 2001). Longer term studies will be needed to assess the time-course of the inflammatory response that we have observed, and it remains to be determined whether there may be important species differences, suggested by strain-specific differences in the response in the mouse brain (Ohmoto et al. 1999). The extent of this response is likely to depend on the tissue and on the dose of viral vector used (Gerdes et al. 2000), and intratumoral delivery may have different effects to those of injection into the normal pituitary gland. However, our findings emphasize the need for cautious and thorough pre-clinical evaluation before considering the use, for pituitary disease in man, of adenoviruses as vectors (Davis \& McNeilly 2001).

\section{Acknowledgements}

This work was supported by the Medical Research Council. We thank the staff of the Marshall Building and Joanne McVerry for their expert technical help.

\section{References}

Barzon L, Bonaguro R, Palu G \& Boscaro M 2000 New perspectives for gene therapy in endocrinology. European Journal of Endocrinology 143 447-466.

Berwaer M, Monget P, Peers B, Mathy-Hartert M, Bellefroid E, Davis JRE, Belayew A \& Martial JA 1991 Multihormonal regulation of the human prolactin gene - expression from $5000 \mathrm{bp}$ of its upstream sequence. Molecular and Cellular Endocrinology 80 53-64.

Byrnes AP, Rusby JE, Wood MJ \& Charlton HM 1995 Adenovirus gene transfer causes inflammation in the brain. Neuroscience 66 1015-1024.

Castro MG 1999 Gene therapy strategies for the treatment of pituitary tumours. Journal of Molecular Endocrinology 22 9-18.

Castro MG, Goya RG, Sosa YE, Rowe J, Larregina A, Morelli A \& Lowenstein PR 1997 Expression of transgenes in normal and neoplastic anterior pituitary cells using recombinant adenoviruses: long term expression, cell cycle dependency, and effects on hormone secretion. Endocrinology 138 2184-2194.

Castro MG, Southgate T \& Lowenstein PR 2001 Molecular therapy in a model neuroendocrine disease: developing clinical gene therapy for pituitary tumours. Trends in Endocrinology and Metabolism 12 $58-64$.
Chan SY, Li K, Piccotti JR, Louie MC, Judge TA, Turka LA, Eichwald EJ \& Bishop DK 1999 Tissue-specific consequences of the anti-adenoviral immune response: implications for cardiac transplants. Nature Medicine 5 1143-1149.

Cheung CC, Ezzat S, Smyth HS \& Asa SL 2001 The spectrum and significance of primary hypophysitis. Journal of Clinical Endocrinology and Metabolism 86 1048-1053.

Davis JRE \& McNeilly AS 2001 Review: Is pituitary gene therapy realistic? Clinical Endocrinology 55 427-433.

Davis JRE, Lowenstein PR, McNeilly AS \& Castro MG 1999 Gene therapy for pituitary tumours. Endocrine-Related Cancer 6 475-481.

Davis JRE, McVerry J, Windeatt S, Lowenstein PR, Castro MG, Lincoln GA \& McNeilly AS 2001 Cell-type specific adenoviral transgene expression in the intact ovine pituitary gland after stereotaxic delivery: an in vivo system for long-term multiple parameter evaluation of human pituitary gene therapy. Endocrinology 142 795-801.

Dewey RA, Morrissey G, Cowsill CM, Stone D, Bolognani F, Dodd NJF, Southgate TD, Klatzmann D, Lassmann H, Castro MG \& Lowenstein PR 1999 Chronic brain inflammation and persistent herpes simplex virus 1 thymidine kinase expression in survivors of syngeneic glioma treated by adenovirus-mediated gene therapy: implications for clinical trials. Nature Medicine 5 1256-1263.

Gerdes CA, Castro MG \& Lowenstein PR 2000 Strong promoters are the key to highly efficient, noninflammatory and noncytotoxic adenoviral-mediated transgene delivery into the brain in vivo. Molecular Therapy 2 330-338.

Kajiwara K, Byrnes AP, Charlton HM, Wood MJ \& Wood KJ 1997 Immune responses to adenoviral vectors during gene transfer in the brain. Human Gene Therapy 10 253-265.

Lee EJ, Anderson LM, Thimmapaya B \& Jameson JL 1999 Targeted expression of toxic genes directed by pituitary hormone promoters: a potential strategy for adenovirus-mediated gene therapy of pituitary tumors. Journal of Clinical Endocrinology and Metabolism 84 786-794.

Lee EJ, Thimmapaya B \& Jameson JL 2000 Stereotactic injection of adenoviral vectors that target gene expression to specific pituitary cell types: implication for gene therapy. Neurosurgery 46 1461-1468.

Lignereux Y, Regodon S, Marty M-H, Franco A \& Bubien A 1991 Encephalic ventricles of the ewe (Ovis aries L.): conformation, relations and stereotaxic topography. Acta Anatomica 141 82-84.

Marshall E 1999 Gene therapy death prompts review of adenovirus vector. Science 286 2244-2245.

Mori Y, Takeuchi Y, Shimada M, Hayashi S \& Hoshino K 1990 Stereotaxic approach to hypothalamic nuclei of the Shiba goat with radiographic monitoring. Japanese Journal of Veterinary Science $\mathbf{5 2}$ 339-349.

Neill JD, Lois C, Musgrove L, Duck W \& Sellers JC 1998 High efficiency method for gene transfer in normal pituitary gonadotropes: adenoviral-mediated expression of $G$ protein-coupled receptor kinase 2 suppresses luteinizing hormone secretion. Endocrinology 140 2562-2569.

Ohmoto Y, Wood MJ, Charlton HM, Kajiwara K, Perry VH \& Wood KJ 1999 Variation in the immune response to adenoviral vectors in the brain: influence of mouse strain, environmental conditions and priming. Gene Therapy 6 471-481.

Southgate TD, Windeatt S, Smith-Arica J, Gerdes CA, Perone MJ, Morris ID, Davis JRE, Klatzmann D, Lowenstein PR \& Castro MG 2000 Transcriptional targeting to anterior pituitary lactotrophic cells using recombinant adenovirus vectors in vitro and in vivo in normal and estrogen/sulpiride-induced hyperplastic anterior pituitaries. Endocrinology 141 3493-3505.

Southgate TD, Stone D, Williams JC, Lowenstein PR \& Castro MG 2001 Long-term transgene expression within the anterior pituitary gland in situ: impact on circulating hormone levels, cellular and antibody-mediated immune responses. Endocrinology 142 464-476. 
Takasuka N, White MRH, Wood CD, Robertson WR \& Davis JRE 1998 Dynamic changes in prolactin promoter activation in individual living lactotrophic cells. Endocrinology 139 1361-1368.

Thomas CE, Schiedner G, Kochanek S, Castro MG \& Lowenstein PR 2000 Peripheral infection with adenovirus causes unexpected long-term brain inflammation in animals injected intracranially with first-generation, but not with high-capacity, adenovirus vectors: toward realistic long-term neurological gene therapy for chronic diseases. PNAS 97 7482-7487.

Thomas CE, Birkett D, Anozie I, Castro MG \& Lowenstein PR 2001 Acute direct adenoviral vector cytotoxicity and chronic, but not acute, inflammatory responses correlate with decreased vector-mediated transgene expression in the brain. Molecular Therapy 3 36-46.

Tripathy SK, Black HB, Goldwasser E \& Leiden JM 1996 Immune responses to transgene-encoded proteins limit the stability of gene expression after injection of replication-deficient adenovirus vectors. Nature Medicine 2 545-550.
Windeatt S, Southgate TD, Dewey RA, Bolognani F, Perone MJ, Larregina AT, Maleniak TC, Morris ID, Goya RG, Klatzmann D, Lowenstein PR \& Castro MG 2000 Adenovirus-mediated herpes simplex virus type- 1 thymidine kinase gene therapy suppresses oestrogen-induced pituitary prolactinomas. Journal of Clinical Endocrinology and Metabolism 85 1296-1305.

Wood MJ, Charlton HM, Wood KJ, Kajiwara K \& Byrnes AP 1996 Immune responses to adenovirus vectors in the nervous system. Trends in Neuroscience 19 497-501.

Yang Y, Nunes FA, Berencsi K, Furth EE, Gonczol E \& Wilson JM 1994 Cellular immunity to viral antigens limits E1-deleted adenoviruses for gene therapy. PNAS 91 4407-4411.

Received 22 October 2001

Accepted 28 January 2002 